\title{
A promising technique for easier single incision laparoscopic cholecystectomy: needle grasper traction of gallbladder
}

\author{
Oguzhan Sunamak ${ }^{1}$, Turgut Donmez ${ }^{2}$, Sina Ferahman ${ }^{3}$, Server Sezgin Uludag ${ }^{3}$, Huseyin Imam Avaroglu ${ }^{2}$ \\ 'Department of General Surgery, Haydarpasa Numune Training and Research Hospital, Istanbul, Turkey \\ ${ }^{2}$ Department of General Surgery, Lutfiye Nuri Burat State Hospital, Istanbul, Turkey \\ ${ }^{3}$ Department of General Surgery, Cerrahpasa Medicine Faculty, Istanbul, Turkey
}

Videosurgery Miniinv

DOI: https://doi.org/10.5114/wiitm.2018.75849

\begin{abstract}
Introduction: Laparoscopic cholecystectomy (LC) is the primary treatment method for benign gallbladder diseases. Single incision laparoscopic cholecystectomy (SILC) was reported to be superior in terms of work return, cosmetic results, and post-operative pain, but limited maneuver capacity and overlapping of hand tools are technical difficulties associated with SILC that endanger patient safety.

Aim: To perform SILC using a needle grasper for gallbladder traction, thus simplifying the dissection of Calot's triangle. Material and methods: The files of patients who underwent elective LC for gallbladder stone and polyps in general surgery clinics between December 2013 and December 2014 were analyzed retrospectively. The patients were divided into two groups: needle-grasper-assisted SILC (nSILC) and conventional laparoscopic cholecystectomy (CLC). Age, gender, height, weight, body mass index, visual analog scale (VAS) scores, ASA score, duration of operation, duration of post-operative hospital stay, complications, drain use, conversion to open and conventional technique, and oral feeding beginning time were analyzed.

Results: There were no per-operative or post-operative complications in either of the groups, and no significant differences were found between the groups in terms of complications. The mean duration of the operation was significantly longer in the nSILC group. There was no difference between the groups in terms of hospital stay. The mean visual analogue scale (VAS) scores in conventional nSILC were significantly lower for all hours. The patient satisfaction in terms of cosmetic results was better in the nSILC group.

Conclusions: Needle-grasper-assisted SILC reduces the number of tools that need to be held by surgeons; it also provides safe dissection, better cosmetic results, and less post-operative pain in elective cases.
\end{abstract}

Key words: laparoscopic cholecystectomy, single port, gallstone disease.

\section{Introduction}

Laparoscopic cholecystectomy (LC) is the most preferred method for treating benign gallbladder diseases [1]. Minimally invasive techniques have been used worldwide by general surgeons since the end of the 1980s. Many studies all over the world have been conducted since the first single incision laparoscopic cholecystectomy (SILC) was reported in 1997 [2]. Today, patients prefer less operation scarring, and SILC was reported to be superior in terms of earlier work return, better cosmetic results, and less post-operative pain [3, 4]. However, the limited maneuver area and overlapping of hand tools create technical difficulties associated with SILC that endanger patient safety [5]. The critical view of safety

\section{Address for correspondence}

Turgut Donmez MD, Department of General Surgery, Lutfiye Nuri Burat State Hospital, 34300 Istanbul, Turkey, phone: +90 5347400967, e-mail: surgeont73@hotmail.com 
(CVS) to avoid biliary tract injury was introduced for the first time by Strasberg et al., and this concept has been accepted by surgeons all over the world [6]. Exposing Calot's triangle and making a safe dissection are very important to avoid biliary tract injury. Gallbladder traction is a problem in SILC for which various techniques such as suture traction have been proposed.

\section{Aim}

We performed SILC by using a needle grasper to gain traction of the gallbladder, thus simplifying the exposure and dissection of Calot's triangle. Here, we present our experience in using needle-grasper-assisted SILC (nSILC) and evaluate its safety and usability by comparing this technique to conventional LC (CLC).

\section{Material and methods}

The files of patients who underwent elective LC for gallbladder stones or polyps in general surgery clinics between December 2013 and December 2014 were analyzed retrospectively. Patients between 18 to 80 years of age with ASA I, II, and III and diagnoses of gallbladder stones or polyps were included in the study.

Written informed consent from all patients was taken prior to the operation. The patients comprised two groups: the nSILC group (58 patients) and the CLC group (60 patients). The age, gender, height, weight, body mass index (BMI), visual analog scale
(VAS) score at the $1^{\text {st }}, 6^{\text {th }}, 12^{\text {th }}$, and $24^{\text {th }} \mathrm{h}$, American Society of Anesthesiologists (ASA) score, duration of operation, duration of post-operative hospital stay, complications, drain use, conversion to open and conventional technique, and oral feeding beginning time were analyzed. The benign gallbladder disease was diagnosed through an ultrasound examination in all patients. History of abdomen surgery, bleeding diathesis, oral or intra-venous anti-coagulant use, pregnancy, gallbladder malignancy, and acute cholecystitis were exclusion criteria. The patients underwent either SILC or conventional LC under general anesthesia by two experienced surgeons. A single dose of 1-g intravenous first-generation cephalosporin was used for prophylaxis, and post-operative analgesia was provided with non-steroidal anti-inflammatory drugs (NSAIDs). The patients were called for post-operative control on the $7^{\text {th }}$ and $21^{\text {st }}$ days, and they were checked for incisional hernia at the end of the first year. Cosmetic satisfaction of the surgical scar was rated on a scale from 0 (worst) to 10 (best) and was evaluated at the 1-month follow-up visit.

This study was approved by the Ethics Committee of Haseki Research and Training Hospital on 11 November 2015 with approval number 272.

In nSILC, a two-cm vertical skin incision was performed on the umbilicus; subcutaneous tissue were passed, linea alba were incised, and the abdominal cavity was accessed. A flexible SILS port (SILS port, Covidien, USA) was placed through the incision and $12 \mathrm{~mm} \mathrm{Hg}$ of pressure pneumoperitoneum was
A

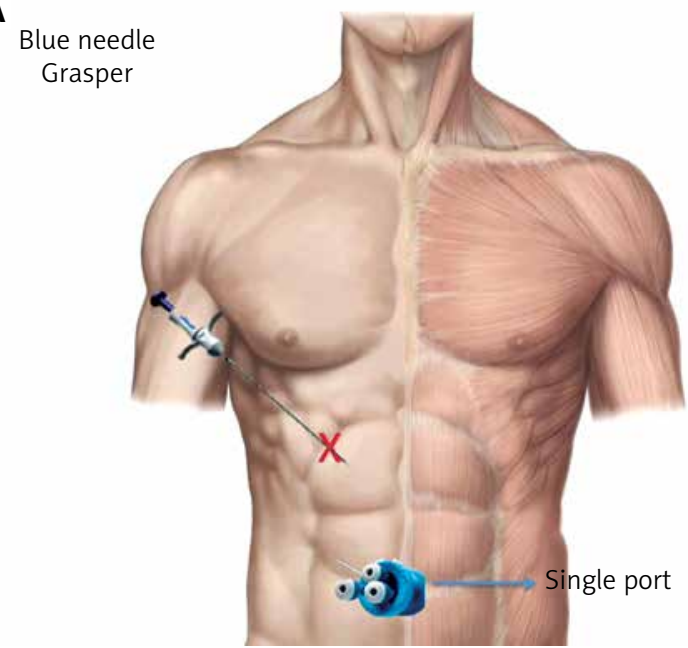

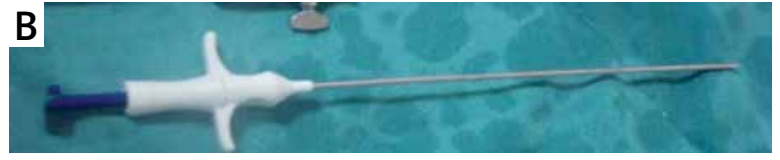

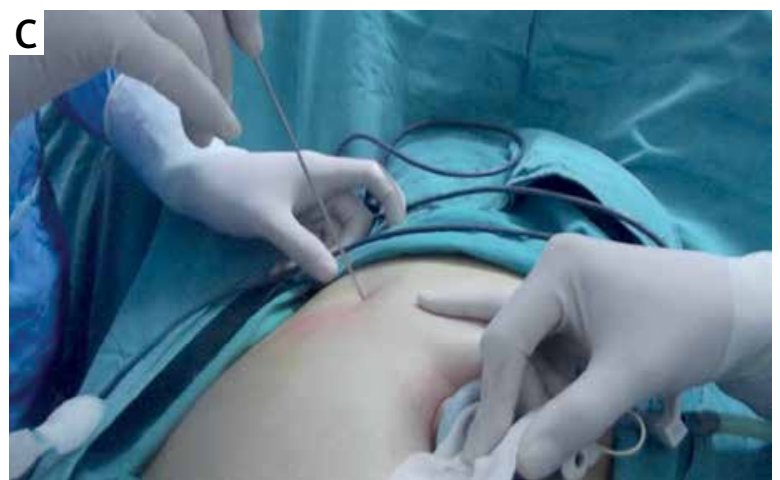

Photo 1. A - Schematic view of the needle port entry point and single port placement. B - Photograph of the needle port entry point and single port placement on the patient. $\mathbf{C}$ - Needle grasper 
formed. A 10-mm trocar through the SILS port was introduced and the intra-abdominal cavity was explored with a 30-degree, 10-mm optical camera. Two other $5-\mathrm{mm}$ trocars were also introduced through the SILS port. The needle grasper (Needle grasper, Blue surgical Inc., UK) was inserted on the midclavicular line $1 \mathrm{~cm}$ below the costal arch without making a skin incision (Photos $1 \mathrm{~A}, \mathrm{~B}$ ). The gallbladder fundus was grasped, and traction to the caudal and lateral

A
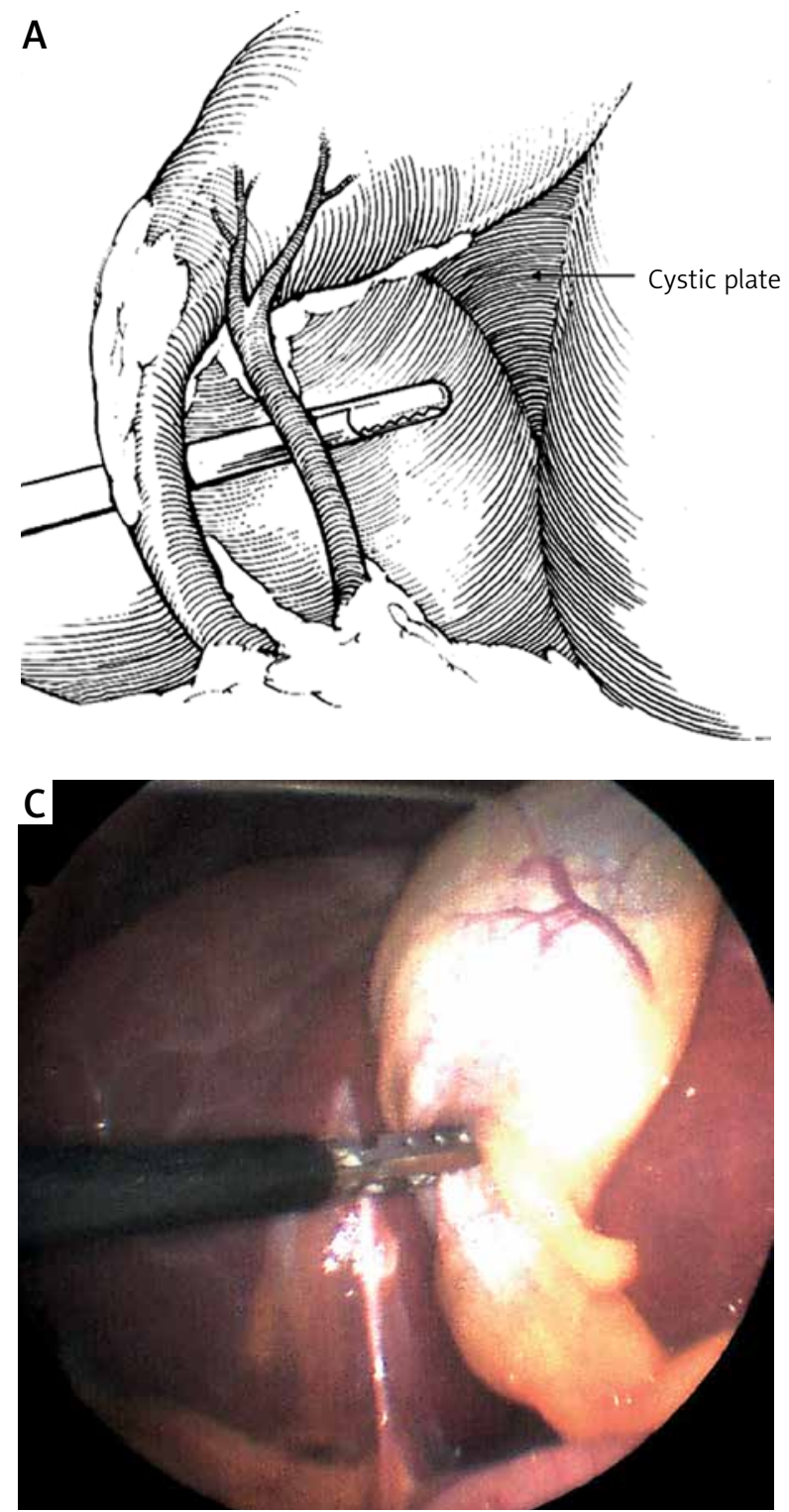

way was applied (Photo 2 B). The neck of gallbladder was grasped with a Roticulator grasper (Covidien, USA) and positioned (Photo $2 \mathrm{C}$ ), and Calot's triangle was dissected using an endodissector, scissors, and a hook (Photos 2 A, D). The cystic duct and artery were isolated. The serosa of the gallbladder was dissected from Glisson's capsule using an endo-hook. The needle grasper was used to position the gallbladder medially and laterally throughout the oper-
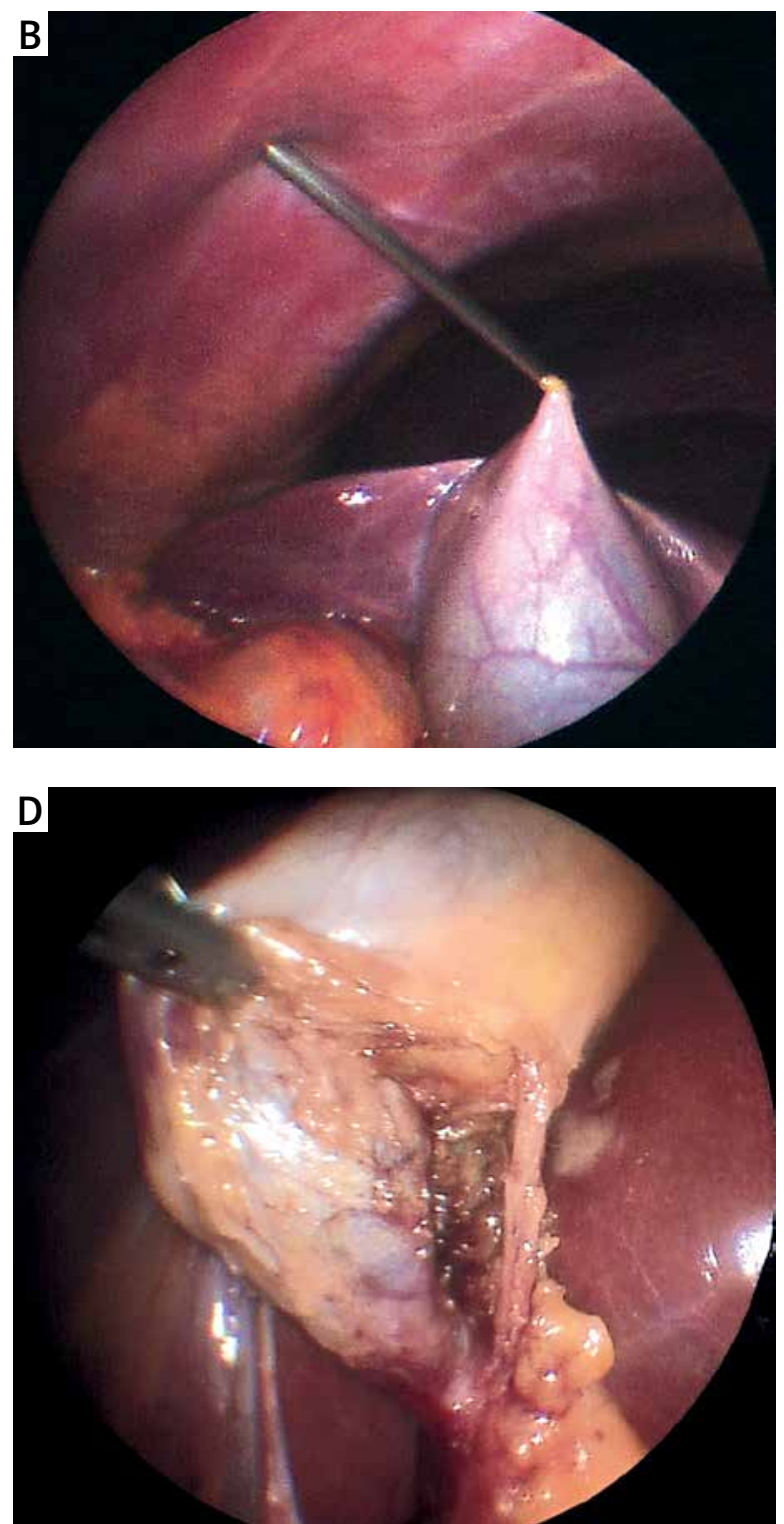

Photo 2. A - In this figure showing the critical view of safety, Calot's triangle is exposed but the common bile duct is not. The gall bladder was separated from the cystic plate at its base so that it would be clear of any ductal or vascular structure and it can be clearly seen that only the cystic duct and artery enter the gallbladder. B - Grasping of gallbladder with needle grasper. C - Traction of gallbladder toward liver dome with needle grasper. D - Dissection of gallbladder which is suspended with needle grasper 
ation. The cystic duct and artery were ligated with 5-mm endoclips (EndoClip, Covidien, Dublin, Ireland) and cut. The needle grasper was removed after the gallbladder was completely separated from the liver bed, and its insertion point was dressed without suturing. Following the bleeding control, the drain was placed, if needed. The gallbladder was grasped with an endo-clinch and removed along with the SILS port together. The linea alba and skin were closed with 0 polypropylene and 3/0 rapid vicryl sutures (Ethicon Inc., Somerville, NJ, USA), respectively.

The patients in the conventional LC group were operated on using a standard four-trocar technique.

\section{Statistical analysis}

The ASA values, complication, co-morbidity, history of abdominal surgery, and drain use were evaluated using the $\chi^{2}$ test. Age, height, weight, $\mathrm{BMI}$, duration of operation, and VAS scores were analyzed with Student's $t$-test. As the discharge and oral feeding beginning time did not exhibit normal distributions using the Kolmogorov-Smirnov test, Mann-Whitney's $U$ test was used to compare the two groups in terms of these parameters.

\section{Results}

The $\mathrm{nSILC}$ and conventional LC groups were composed of 38 females and 20 males and 43 females and 17 males, respectively. The patients in the nSILC group were significantly younger than those of the conventional LC group: the mean ages were 48.09 $\pm 12.634(24-75)$ and $53.70 \pm 15.872(23-80)$ years, respectively $(p=0.036)$. The mean BMI was lower in the nSILC group (64 $\pm 3.372(19.6-38.06)$ vs. 27.88 \pm 3.234 (19.9-34); $p=0.037$ ). ASA III patients were more prevalent in the conventional LC group ( $p=$ 0.040) (Table I).

The patients exhibited similar occurrences of gallbladder stones (81\% and $80 \%$ ) and gallbladder polyps (19\% and $20 \%$ ) in the NSILC and conventional LC groups, respectively.

There was no incisional hernia in any of the patients at the end of the first year of follow-up. There was no important per-operative or early post-operative complication except per-operative bleeding, wound infection, and gallbladderinjury in both groups, and there was no significant difference between the groups in terms of complications $(p=0.161)$.

Table I. Patient demographics

\begin{tabular}{|c|c|c|c|}
\hline Parameter & $\mathrm{nSILC}(n=58)$ & $\operatorname{CLC}(n=60)$ & $P$-value \\
\hline Age [years] & $48.09 \pm 12.634(24-75)$ & $53.70 \pm 15.872(23-80)$ & 0.036 \\
\hline Gender (male/female) & $20 / 38$ & $17 / 43$ & 0.493 \\
\hline Indication (stone/polyp) & $47 / 11$ & $48 / 12$ & 0.887 \\
\hline Gallbladder stone & $47(81 \%)$ & $48(80 \%)$ & \\
\hline Gallbladder polyp & $11(19 \%)$ & $12(20 \%)$ & \\
\hline Height [cm] & $168.10 \pm 4.392(155-178)$ & $165.47 \pm 8.148(151-186)$ & 0.031 \\
\hline Weight [kg] & $75.09 \pm 8.350(60-110)$ & $76.43 \pm 11.201(50-110)$ & 0.462 \\
\hline $\mathrm{BMI}\left[\mathrm{kg} / \mathrm{m}^{2}\right]$ & $26.64 \pm 3.372(19.6-38.06)$ & $27.88 \pm 3.234(19.9-34)$ & 0.037 \\
\hline $\operatorname{ASA}\left(1 / 2 / 3^{*}\right)$ & $35 / 20 / 3$ & $27 / 21 / 12$ & $0.040^{*}$ \\
\hline Lower abdomen surgery & $8(13.79 \%)$ & $11(18.33 \%)$ & 0.726 \\
\hline Comorbidity: & $24(41.37 \%)$ & $42(69.7 \%)$ & 0.114 \\
\hline $\mathrm{DM}$ & $12(20.68 \%)$ & $19(31.54 \%)$ & \\
\hline HT & $8(13.8 \%)$ & $15(25 \%)$ & \\
\hline COPD & $4(6.9 \%)$ & $6(10 \%)$ & \\
\hline Miscellaneous & 0 & $2(3.33 \%)$ & \\
\hline
\end{tabular}

nSILC - needle-grasper assisted single port laparoscopic cholecystectomy, CLC - conventional laparoscopic cholecystectomy, BMI - body mass index, ASA American Society of Anesthesiologists score, DM - diabetes mellitus, HT - hypertension. 
One patient in the nSILC group developed a wound infection, and one patient from each group had per-operative gallbladder injury. The mean operation duration was significantly longer in the nSILC group compared to that of the conventional LC group (87.72 \pm 12.105 (74-110) vs. $59.02 \pm 6.809$ (45-82) min, respectively; $p \leq 0.001)$. There was no difference between the groups in terms of hospital stay.

As shown in Table II, the mean doses of analgesic injection were $2.88 \pm 0.75(218.5 \mathrm{mg})$ and 1.84 $\pm 0.57(148 \mathrm{mg})$ in the CLC and nSILS groups, respectively. Each dose consists of $75 \mathrm{mg}$ of diclofenac so- dium. The mean VAS scores in the conventional LC and nSILC groups according to post-operative hours were VAS 1: $64 \pm 0.485 / 7.57 \pm 0.500(p \leq 0.001)$; VAS 6: $3.41 \pm 0.531 / 4.12 \pm 0.49(p \leq 0.001)$; VAS $12: 1.71$ $\pm 0.451 / 2.5 \pm 0.504(p \leq 0.001)$; and VAS $24: 0.29$ $\pm 0.459 / 1.02 \pm 0.390(p \leq 0.001)$, respectively (Table III).

In the CLC group, the mean dose of analgesic injection was $2.88 \pm 0.75$ (218.5 mg); in the SILS group, this value was $1.84 \pm 0.57$ (148 mg). Each dose consisted of $75 \mathrm{mg}$ of diclofenac sodium (Table II).

Drain use was not different between the groups (3 patients in the nSILC group and 4 patients in the

Table II. Operative parameters

\begin{tabular}{|c|c|c|c|}
\hline Parameter & $\mathrm{nSILC}(n=58)$ & $\operatorname{CLC}(n=60)$ & $P$-value \\
\hline Duration of surgery [min] & $87.72 \pm 12.105(74-110)$ & $59.02 \pm 6.809(45-82)$ & $<0.001$ \\
\hline Oral feeding time $[\mathrm{h}]$ & $6.45 \pm 0.776(5-8)$ & $6.67 \pm 0.837(7-9)$ & 0.109 \\
\hline Hospital stay period [day] & $1.13 \pm 0.329(1-2)$ & $1.15 \pm 0.444(1-3)$ & $>0.999$ \\
\hline Injectable analgesic dose & $1.84 \pm 0.57$ & $2.88 \pm 0.75$ & $<0.001$ \\
\hline Additional port & 0 & 0 & $>0.999$ \\
\hline Drain & 3 & 4 & 0.782 \\
\hline Complication: & $2(3.44 \%)$ & $2(3.33 \%)$ & 0.161 \\
\hline Biliary duct injury & 0 & 0 & \\
\hline Wound site infection & 0 & $1(1.66 \%)$ & \\
\hline Conversion to open & 0 & 0 & $>0.999$ \\
\hline Blood loss (minimal/others)* & 3 & 4 & 0.782 \\
\hline Easy cholecystectomy & $45(77.58 \%)$ & $47(78.33 \%)$ & 0.856 \\
\hline Difficult cholecystectomy: & $13(22.42 \%)$ & $13(21.66)$ & 0.756 \\
\hline Gallbladder injury & $1(1.72 \%)$ & $1(1.66 \%)$ & \\
\hline Impacted stone in the neck of the GB & $7(12.06 \%)$ & $6(10 \%)$ & \\
\hline Adhesions in the triangle of Calot & $5(8.62 \%)$ & $6(10 \%)$ & \\
\hline Cosmetic score & $9.62 \pm 0.55$ & $6.23 \pm 0.72$ & $<0.001$ \\
\hline CVS & $53(91.38 \%)$ & - & \\
\hline
\end{tabular}

Table III. Post-operative visual analogue scale (VAS) scores

\begin{tabular}{|lccc|}
\hline VAS score & nSILC $(n=58)$ & CLC $(n=60)$ & $P$-value \\
\hline${\text { Postoperative } 1^{\text {st }} \mathrm{h}}^{\text {th }}$ & $1.64 \pm 0.485$ & $7.57 \pm 0.500$ & $<0.001$ \\
\hline${\text { Postoperative } 6^{\text {th }}}^{\text {th }}$ & $3.41 \pm 0.531$ & $4.12 \pm 0.490$ & $<0.001$ \\
\hline${\text { Postoperative } 12^{\text {th }}}^{\text {th }}$ & $1.71 \pm 0.451$ & $2.5 \pm 0.504$ & $<0.001$ \\
\hline Postoperative $24^{\text {h }}$ & $0.29 \pm 0.459$ & $1.02 \pm 0.390$ & $<0.001$ \\
\hline
\end{tabular}



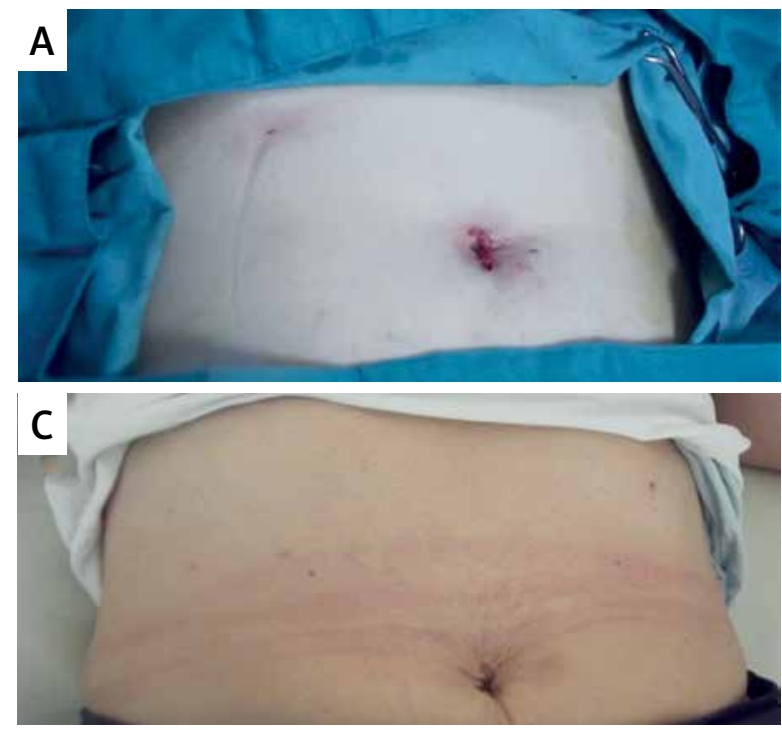

conventional LC group; $p=0.782$ ) (Table II). There was no conversion to open surgery in any of the groups.

Cosmetic satisfaction of the patients in terms of surgical scar was rated on a scale from 0 (worst) to 10 (best) and was evaluated at the 1-month follow-up visit (Table II). The patient satisfaction in terms of cosmetic results was very good in the nSILC group (Photo 3).

\section{Discussion}

Laparoscopic cholecystectomy is the gold standard method for treating benign gallbladder diseases. In recent years, less trauma and better cosmetic results have been sought by decreasing the number of trocars or entry ports. Thus, the tendency for endoscopic operations to use single-port LC and natural orifices has increased. The SILC can be proposed to have better cosmetic results, fewer complications, and decreased post-operative pain along with faster healing times $[7,8]$. However, the superiority of SILC over CLC is still debatable. In spite of less post-operative pain and better cosmetic results, patients' safety remains the priority. SILS is technically more difficult due to its limited maneuver area as well as the overlapping of working tools and its limited triangulation, which result in insufficient traction of the gallbladder and thus insufficient CVS during dissection of Calot's triangle [9]. So, concerns regarding potential biliary complications have persisted, and previous studies on SILC were conducted on select-

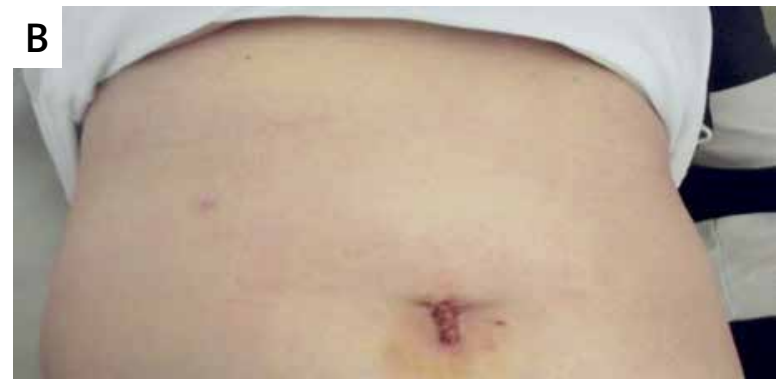

Photo 3. A - View of the skin of the patient following the operation, $\mathbf{B}$ - 10 days later, $\mathbf{C}$ 1 month later

ed patients excluding such challenging situations as acute cholecystitis, obesity, and history of previous abdominal surgery [10].

Many methods have tried to expose Calot's triangle and hang the gallbladder to provide a safe dissection. Srikanth et al. describe how they hung the gallbladder using a suture, which was passed through its fundus [11]. Another study reported a successful traction of a gallbladder and exposure of Calot's triangle by passing the suture through the infundibulum and taking its tips out of the abdomen at the right subcostal area [12].

Raman et al. used a magnetic anchoring and guidance system (MAGS) in SILS and NOTES, where intra-abdominally located instruments could be manipulated by using an extra-abdominal handy-type magnet to expose Calot's triangle [13]. Tae-Seok et al., in their study on 485 patients, inserted a needle-scopic grasper on the right upper quadrant and performed SILC by grasping the infundibulum of the gallbladder with it and retracting the liver by using a snake liver retractor. Comparing the SILC to CLC, they found no difference in terms of post-operative pain between the groups but a higher intra-operative complication rate in the CLC group [14]. Donmez et al. emphasized in their retrospective clinical study that needle-grasper-assisted SILS port cholecystectomy prevented technical difficulty due to overlapping of hand tools and made it easy for the surgeon compared to other techniques [15].

We inserted a needle grasper on the right subcostal area into the abdominal cavity, grasped the 
fundus, and hung the gallbladder in our study. With the help of a needle grasper, the gallbladder was hung up towards the right axilla; the cystic artery and duct were dissected with an endodissector and endo-hook, clipped, and cut. The needle grasper provided the exposure of Calot's triangle and a safe area for dissection by enabling the surgeon to manipulate the gallbladder. Also, the number of working tools through the SILS port was decreased, thus preventing overlap. The only difference in our technique from the SILS is the additional insertion of a working tool (i.e., a needle grasper) at a different point without using a trocar, which made the operation easier compared to SILS. The promising aspects of our technique are as follows. First, direct insertion of a 2- to 3-mm-diameter hand tool without using an additional trocar resulted in a minimal entry point scar and better cosmetic appearance. Also, the surgeon is able to use the needle grasper with their left hand, thus eliminating the probable overlapping of hand tools and discordance when an assistant holds it instead. This allows the surgeon to create a desired triangular shape of the dissection area as in CLC. We did not observe any major complications such as choledochal or vascular injury in our study, but a hemovac drain was placed in 3 patients of the nSILC group and 4 patients in the CLC group due to blood leakage from the liver bed and removed on the first post-operative day. However, a disadvantage of our technique is that it is only applicable in elective cases because of the impossibility of grasping and hanging the gallbladder in acute cholecystitis patients due to edema and inflammation.

Tyagi et al., in their randomized clinical study on 150 cases, compared cosmetic results between SILC and CLC and found that SILC had significantly better results in which a minimal wound scar was observed $(6.25 \pm 1.24-4.71 \pm 1.04 ; p<0.05)$ [16]. Ye et al. found better cosmetic results in SILC compared to $\mathrm{CLC}$, but the results were not statistically significant in their randomized clinical series of 200 cases $(0.822$ $\pm 0.076-0.808 \pm 0.086 ; p=0.102$ ) [17]. Komine et al. retrospectively compared needle grasper-assisted SILC to CLC and reported that there was no wound scar at the needle-grasper entry point; they also emphasized the very good cosmetic results [18].

We believe that insertion of a needle grasper directly without the use of a trocar provides better cosmetic results. However, such direct insertion of a hand tool may increase the risk of port-site infec- tion when contamination with infected bile is present. In our method, the outer sheet of the needle grasper works as if it was a trocar and might provide protection against port-site infection. This right subcostal insertion of the grasper needle also eliminates overlapping of working tools and the video optic camera by positioning the gallbladder in an optimal position and decreasing the number of instruments working through the SILS port. We also did not observe any wound scar at the needle-grasper insertion point on the $21^{\text {st }}$ post-operative day.

Pain is the most frequent complaint of LC patients during the early post-operative period. Tyagi et al., in their randomized study, reported that the pain was significantly less in the SILC group compared to that of the CLC group. They found better post-operative $4^{\text {th }}$ and $24^{\text {th }} \mathrm{h}$ VAS scores in the SILC group $(p<0.001)$ [16]. There are similar clinical studies that support these findings $[19,20]$, but there are other studies that report no difference in terms of pain between the groups [21, 22]. We found that the $\mathrm{nSILC}$ group had insignificantly less pain at the $1^{\text {st }}, 6^{\text {th }}, 12^{\text {th }}$, and $24^{\text {th }} \mathrm{h}$ compared to the CLC group $(p<0.001)$.

\section{Conclusions}

The needle-grasper-assisted SILC method reduces overlapping of hand tools and the optical camera and decreases the number of hand tools inserted through the SILS port, thus reducing the number of hand tools in the hands of surgeons. In this study, we showed that Calot's triangle can be exposed and CVS can be provided easily by positioning the gallbladder with the help of a needle grasper. Better cosmetic results and less post-operative pain are further advantages of this technique.

\section{Conflict of interest}

The authors declare no conflict of interest.

\section{References}

1. Duncan CB, Riall TS. Evidence-based current surgical practice: calculous gallbladder disease. J Gastrointest Surg 2012; 16 : 2011-25.

2. Navarra G, Pozza E, Occhionorelli S, et al. One-wound laparoscopic cholecystectomy. Br J Surg 1997; 84: 695.

3. Ichikawa M, Akira S, Mine K, et al. Evaluation of laparoendoscopic single-site gynecologic surgery with a multitrocar access system. J Nippon Med Sch 2011; 78: 235-40. 
4. Omori T, Oyama T, Akamatsu H, et al. Transumbilical single-incision laparoscopic distal gastrectomy for early gastric cancer. Surg Endosc 2011; 25: 2400-4.

5. Wagner MJ, Kern H, Hapfelmeier A, et al. Single-port cholecystectomy versus multiport cholecystectomy: a prospective cohort study with 222 patients. World J Surg 2013; 37: 991-8.

6. Strasberg SM, Brunt LM. Rationale and use of the critical view of safety in laparoscopic cholecystectomy. J Am Coll Surg 2010; 211: $132-8$.

7. Markar SR, Karthikesalingam A, Thrumurthy S, et al. Single-incision laparoscopic surgery (SILS) vs. conventional multiport cholecystectomy: systematic review and meta-analysis. Surg Endosc 2012; 26: 1205-13.

8. Han HJ, Choi SB, Kim WB, Choi SY. Single-incision multiport laparoscopic cholecystectomy: things to overcome. Arch Surg 2011; 146: 68-73.

9. Barband A, Fakhree MB, Kakaei F, Daryani A. Single-incision laparoscopic cholecystectomy using glove port in comparison with standard laparoscopic cholecystectomy SILC using glove port. Surg Laparosc Endosc Percutan Tech 2012; 22: 17-20.

10. Cheon SU, Moon JI, Choi IS. Risk factors for prolonged operative time in single-incision laparoscopic cholecystectomy. Ann Surg Treat Res 2015; 89: 247-53.

11. Srikanth G, Shetty N, Babu P. A technique for gallbladder fundal traction in single-incision laparoscopic cholecystectomy. Surg Laparosc Endosc Percutan Tech 2011; 21: 239-41.

12. Horisberger K, Grossen E, Schöb O. How to meet the challenge of flexible exposure of the calot triangle in SILS cholecystectomy. Surg Laparosc Endosc Percutan Tech 2012; 22: 63-5.

13. Raman JD, Scott DJ, Cadeddu JA. Role of magnetic anchors during laparoendoscopic single site surgery and NOTES. J Endourol 2009; 23: 781-6.

14. Kim TS, Kim KH, An CH, Kim JS. Single center experiences of needle-scopic grasper assisted single incision laparoscopic cholecystectomy for gallbladder benign disease: comparison with conventional 3-port laparoscopic cholecystectomy. Ann Surg Treat Res 2016; 91: 233-8.

15. Donmez T, Uzman S, Ferahman S, et al. New advantageous tool in single incision laparoscopic cholecystectomy: the needle grasper. Videosurgery Miniinv 2016; 11: 38-43.

16. Tyagi S, Sinha R, Tyagi A. Single incision laparoscopic cholecystectomy: less scar, less pain. J Minim Access Surg 2017; 13: 118-23.

17. Ye G, Qin Y, Xu S, et al. Comparison of transumbilical single-port laparoscopic cholecystectomy and fourth-port laparoscopic cholecystectomy. Int J Clin Exp Med 2015; 15: 7746-53.

18. Komine O, Suzuki H, Watanabe $M$, et al. Single-incision laparoscopic cholecystectomy with an additional needle grasper: a novel technique. J Nippon Med Sch 2015; 82: 43-9.

19. Hao L, Liu M, Zhu H, Li Z. Single-incision versus conventional laparoscopic cholecystectomy in patients with uncomplicated gallbladder disease: a meta-analysis. Surg Laparosc Endosc Percutan Tech 2012; 22: 487-97.

20. Arezzo A, Scozzari G, Famiglietti F, et al. Is single-incision laparoscopic cholecystectomy safe? Results of a systematic review and meta-analysis. Surg Endosc 2013; 27: 2293-304.
21. Luna RA, Nogueira DB, Varela PS, et al. A prospective, randomized comparison of pain, inflammatory response, and shortterm outcomes between single port and laparoscopic cholecystectomy. Surg Endosc 2013; 27: 1254-9.

22. Madureira FA, Manso JE, MadureiraFo D, Iglesias AC. Randomized clinical study for assessment of incision characteristics and pain associated with LESS versus laparoscopic cholecystectomy. Surg Endosc 2013; 27: 1009-15.

Received: 17.11.2017, accepted: 26.02.2018 